Available online at GSC Online Press Directory

GSC Biological and Pharmaceutical Sciences

e-ISSN: 2581-3250, CODEN (USA): GBPSC2

Journal homepage: https://www.gsconlinepress.com/journals/gscbps

(RESEARCH ARTICLE)

\title{
The isolation, identification and antimicrobial activities of endophytic fungi from
} Azadirachta indica

Ujam Nonye Treasure ${ }^{1,}{ }^{*}$, Abba Chika Christiana ${ }^{2}$, Eze Peter Maduabuchi ${ }^{3}$, Oli Angus Nnamdi 4, Ejikeugwu Chika Ebiye ${ }^{5}$, Ugwu Malachy Chigozie ${ }^{4}$, Okoye Festus Basden Chiedu ${ }^{2}$ and Esimone Charles Okechukwu ${ }^{4}$

1Department of Pharmaceutical Microbiology and Biotechnology, Faculty of Pharmaceutical Sciences, Enugu State

University of Science and Technology, Enugu State, Nigeria.

${ }^{2}$ Department of Pharmaceutical and Medicinal Chemistry, Faculty of Pharmaceutical Sciences, Nnamdi Azikiwe

University, Awka, Anambra State, Nigeria.

${ }^{3}$ Department of Environmental Health Science, Faculty of Health Sciences and Technology, Nnamdi Azikiwe University,

Awka, Anambra State, Nigeria.

${ }^{4}$ Department of Pharmaceutical Microbiology and Biotechnology, Faculty of Pharmaceutical Sciences, Nnamdi Azikiwe

University, Awka, Anambra State, Nigeria.

${ }^{5}$ Department of Applied Microbiology, Faculty of Sciences, Ebonyi State University, Abakaliki, Ebonyi State, Nigeria.

Publication history: Received on 10 June 2020; revised on 18 June 2020; accepted on 19 June 2020

Article DOI: https://doi.org/10.30574/gscbps.2020.11.3.0171

\begin{abstract}
Endophytic microorganisms are the storehouse of novel secondary metabolites that can serve as an excellent source of drugs for different ailment. In this study, we isolated endophytic fungi associated with Azadirachta indica collected from Agulu, Awka, Anambra State, South Eastern Nigeria, identified some of their bioactive secondary metabolites and evaluated their antimicrobial properties. The endophytic fungi were isolated following standard method and the pure culture of the isolates identified morphologically and molecularly. The fungi were subjected to solid-state fermentation on rice medium and the metabolites were extracted using ethyl acetate. The fungal crude extracts were screened for antimicrobial activity. The extracts were further subjected to high-performance liquid chromatography-diode-array detection (HPLC-DAD) analysis for the identification of the bioactive compounds. A total of four endophytic fungi identified as Aureobasidium sp. (AIL1), Sodaria sp. (AIL3), Aspergillus sp. (AIS1) and Penicillium sp. (AIS2) were isolated from the Azadirachta indica. The crude extracts at $1 \mathrm{mg} / \mathrm{mL}$, showed varying degrees of antimicrobial activity against the test fungi and bacteria Iinhibtion zone diameter (IZD) ranged from 2 to $11 \mathrm{~mm}$. The minimum inhibitory concentrations (MICs) of the fungal extracts ranged from 0.0625 to $0.25 \mathrm{mg} / \mathrm{mL}$. The HPLC-DAD analysis revealed the presence Glucobrassicin, Ferulic acid, 4-methoxybenzaldehyde, 12-Hydroxy-16-scalaren, 12-0-deacetyl-12-episcalarin, Ixoside, Citreodrimene F, and Cytosporin D, some of which has been reported to have shown antimicrobial activity. Azadirachta indica possess sundry groups of fungal endophytes that contain secondary metabolites with interesting antimicrobial properties that could be explored in drug discovery.
\end{abstract}

Keywords: Azadirachta indica; Endophytic fungi; Molecular identification; HPLC-DAD analysis; Antimicrobial activity

\section{Introduction}

Infectious and parasitic diseases account for approximately half of the deaths worldwide [1]. Plants have served as sources of medicinal bioactive compounds against numerous forms of ailments for centuries. All plants are inhabited internally by diverse microbial communities comprising bacteria, archaea, fungi, and protista [2,3]. Amazingly, in recent

\footnotetext{
* Corresponding author: Ujam Nonye Treasure
} 
years, microorganisms associated with plants rather than the plants themselves have proved to offer material and products with high therapeutic potential [4].

The term "endophyte" refers to all microorganisms that colonize internal plant tissues for all or part of their lifetime [3]. Endophytes are an under-investigated group of microorganisms that represent a plentiful and renewable source of bioactive and chemically new compounds with potential for exploitation in a wide variety of medical, agricultural, and industrial realms [5]. The association between fungal endophytes and their host plant is due to the result of unique adaptations which enable the endophytes to harmonize their growth with that of their host [6]. They are a taxonomically and ecologically heterogeneous group of organisms; mainly belonging to Ascomycota, coelomycetes, and hyphomycetes $[7,8]$.Recently, many known, as well as new endophytic bioactive metabolites, possessing a wide variety of biological activities as antibiotic, antiviral, anticancer, anti-inflammatory, antioxidant, etc., have been identified $[9,10,11,12,13,14,15]$

Azadirachta indica is a fast-growing evergreen tree common in Afro-Indian regions as well as America [16]. Extracts of the fresh leaves of this plant are reported in folk medicine for their antimicrobial, antimalarial, anthelminthic, antiviral,antiulcer actions $[17,18]$.

An endophyte Geotrichum sp., isolated from the leaves of the A. indica has been reported to produce two new chlorinated epimeric1, 3-oxazinane derivatives that have significant activity against the nematodes Bursaphelenchus xylophilus and Panagrellus redivevus [19]. 'Lavanicin' an antibacterial naphthaquinone was also isolated and characterized from the endophytic Chloridium sp. obtained from root tissues of the A. indica A Juss. This highly functionalized naphthaquinone exhibited strong antibacterial activity against Pseudomonas sp. which are pathogenic to both humans and plants [19]. This study aims at isolating some endophytic fungi from the leaves and stem of $A$. indica, as well as secondary metabolites of these fungi and then investigating the biological potentials of the isolated metabolites. To the best of our knowledge, this is the first report on the isolation of the fungi-Sordaria sp., and Aureobasidium sp. from A. indica.

\section{Material and methods}

\subsection{Plant material}

Fresh leaves and stem of $A$. indica were collected from Agulu, Awka, Anambra State, South-East Nigeria and the plant materials was authenticated by the taxonomist at the Department of Pharmacognosy, Faculty of Pharmaceutical Sciences, Nnamdi Azikiwe University in Agulu of Nigeria. A voucher specimen (PCG474/A/046) was deposited in the herbarium of the above Department.

\subsection{Test organisms}

A total of seven clinical microbial (Five bacterial and two fungi) strains: - Bacillus subtilis, Staphylococcus aureus, Klebsiella pneumoniae, Pseudomonas aeruginosa, Salmonella typhi, Aspergillus niger and Candida albicans were used to evaluate the antimicrobial activity of the isolated fungal endophyte extracts.

\subsection{Isolation and purification of endophytic fungi}

The collected plant materials were subjected to surface sterilization and isolation procedures following the method of Arnold et al. [20] with little modifications. Briefly, the plant materials were first washed several times under running tap water, followed by washing in distilled water. Surface sterilization was then done by sequentially rinsing the plant materials with $70 \%$ ethanol for 30 s; $2 \%$ sodium hypochlorite $(\mathrm{NaOCl})$ for $2-3 \mathrm{~min}$; rinsing in another $70 \%$ ethanol for 2 min and finally with sterile distilled water for 2-3 times. The plant materials were then dried in between folds of sterile filter papers under aseptic conditions. After sterilization, the plant materials were further cut (aseptically) to expose the interior surface to the Malt Extract Agar. The Leaf segments were placed on $9 \mathrm{~cm}$ Petri plates containing malt extract agar (MEA) medium amended with chloramphenicol $500 \mathrm{mg} / \mathrm{mL}$ to suppress bacterial growth [21]. The dishes were sealed with masking tapes and incubated at $28 \pm 1{ }^{\circ} \mathrm{C}$ for 3-7 days. Within the days of incubation, the hyphal tips of fungi growing out from the samples were subsequently transferred onto fresh MEA plates. The procedure of transferring to fresh MEA plates carried out several times in order to obtain pure culture of fungi. The isolated endophytic fungus was subjected to solid state fermentation in 1L Erlenmeyer flask containing sterilized rice medium (prepared by autoclaving a mixture of $100 \mathrm{~g}$ of rice and $00 \mathrm{ml}$ of distilled water). The flask was inoculated with agar blocks containing the fungus and incubated at $25-27^{\circ} \mathrm{C}$ for 21 days. At the completion of fermentation, the fungal secondary metabolites were extracted with ethyl acetate and then concentrated under vacuum at $40{ }^{\circ} \mathrm{C}$. 


\subsection{Identification of the isolated endophytic fungi}

\subsubsection{Macroscopic study}

Morphological study was done by plating the fungi on MEA and incubating for 7 days. The growth appearance was then noted by observing both the back and front views of the plates.

\subsubsection{Microscopic study}

Unknown endophytic fungi were identified by studying their cultural characteristics, spore formations and mycelium. Slides were prepared by tease mount method using Lactophenol Cotton Blue reagent and observed at $\times 40$ and $\times 100$ magnifications.

\subsubsection{Molecular identification}

DNA extraction and PCR

DNA was extracted from culture of endophytic fungi mycelia using a ZR Fungal/Bacterial DNA MiniPrep ${ }^{\mathrm{TM}}$ Kit from Zymo Research Corp, USA according to the manufacturer's protocols. Polymerase Chain reaction (PCR) was then conducted to amplify the internal transcribed spacer (ITS) region of the extracted DNA, including the 5.8s rDNA, using the primers ITS1 (with base sequences 5'-TCCGTAGGTGAACCTGCGG-3') and ITS4 (with base sequences $5^{\prime}$ TCCTCCGCTTATTGATATGC-3') under the following conditions: Initial denaturation at $90^{\circ} \mathrm{C}$ for 15 min; denaturation at $95^{\circ} \mathrm{C}$ for $1 \mathrm{~min}$; annealing at $56^{\circ} \mathrm{C}$ for $1 \mathrm{~min}$ and extension at $72^{\circ} \mathrm{Cfor} 1 \mathrm{~min}$. The PCR process lasted a total of $35 \mathrm{cycles}$ and ended with the extension at $72^{\circ} \mathrm{C}$ for 10 minutes.

\section{Sequencing}

The PCR products were sequenced and the base sequences were compared to the data in Genebank. Blast search of the sequences, to identify the DNA sequence of the fungi, was performed following the link:

http://blast.ncbi.nlm.nih.gov/Blast.cgi?PROGRAM=blastn\&BLAST PROGRAMS=megaBlast\&PAGE TYPE=BlastSearch\& SHOW_DEFAULTS=on\&LINK_LOC=blasthome

\subsection{Screening for antimicrobial activity/determination of minimum inhibitory concentrations (MICs)}

The antimicrobial screening and MIC determination were carried out following our previous method [15].

\subsection{High performance liquid chromatography-diode array detection (HPLC-DAD) assay}

HPLC analysis of the endophyte extract was carried out using a Dionex attached to a photodiode array detector (UVD340S, DionexSoftron GmbH, Germering, Germany). Two milligram (2mg) was reconstituted with 2 ml of HPLC grade methanol, the mixture was sonicated for $10 \mathrm{~min}$ and centrifuged at $3000 \mathrm{rpm}$ for $5 \mathrm{~min}$. Afterward $100 \mu \mathrm{L}$ of the dissolved samples were transferred into HPLC vials containing $500 \mu \mathrm{L}$ of the HPLC grade methanol for analysis. Detection was at 235, 254, 280, and $340 \mathrm{~nm}$. The separation column (125 $\mathrm{mm} \times 4 \mathrm{~mm}$; length $\times$ internal diameter $)$ was pre-filled with Eurospher-10 C18 (Knauer, Germany) and a linear gradient of nanopure water (adjusted to pH 2 by addition of formic acid) and methanol was used as eluent. The absorption peaks for each of the 10 dried fungal metabolite extract were analysed by comparing with those in the HPLC-ultraviolet (UV)/visible database, which contains over 1600 registered compounds.

\subsection{Statistical analysis}

Results of the study were presented as mean \pm Standard error of mean (SEM) of sample replicate, $n=5$. Raw data were analyzed by one way analysis of variance (ANOVA) followed by post-hoc Turkey's test and independent students't-test. Bivariate correlation was used to assess the relationship of the biological assays. The analysis was done using statistical package for social Sciences (SPSS) version 20 for windows. Statistical significance was established when P<0.05. Graphical illustration was carried out using Microsoft excel, 2007. 


\section{Results}

A total of four endophytic fungi coded (AILI, AIS1, AIS2 and AIL3) were isolated from Azadirachta indica. The isolated fungi were generally identified macroscopically and microscopically based on their morphological appearances (Fig. 1 and Table 1). The endophytic fungi AIL1, AIS1 and AIS2 were identified as Aureobasidium sp., Aspergillus sp. and Penicillium sp. respectively (Table 1). The fungus AIL3 was further identified using molecular biology protocols (Table 2). The DNA sequences were determined using BLAST and comparing data at the NCBI GenBank database. The fungus AIL3 was identified using standard Polymerase Chain Reaction (PCR) analysis by ITS-rDNA amplification method as Sordaria sp., a member of Sordariaceae family respectively, with maximum identity and characteristic of $100 \%$ (Table 2).
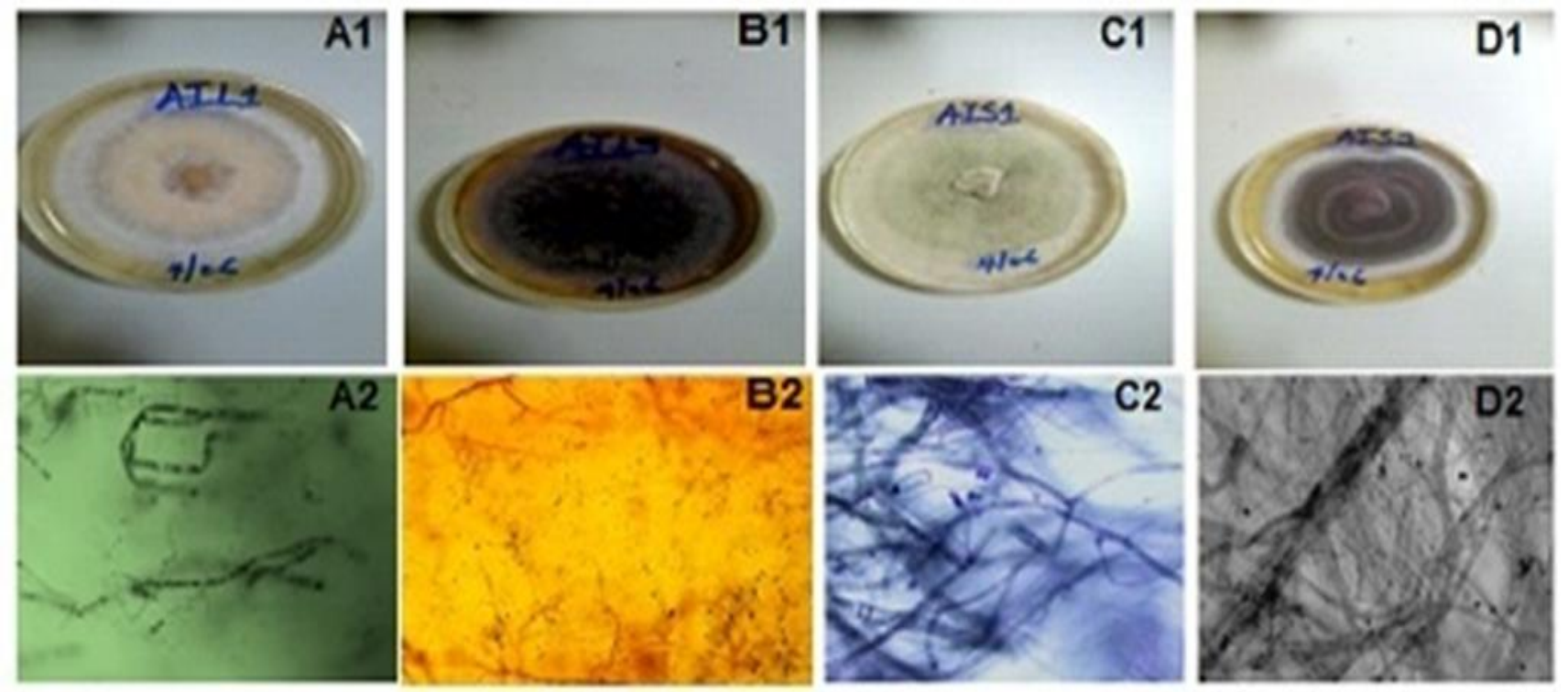

Figure 1 Macroscopic (A1, B1, C1 and D1) and microscopic (A2, B2, C2 and D2) characteristics of the isolated endophytic fungi (AIL1, AIL3, AIS1 \& AIS2) isolated from the leaves and stem of the medicinal plant Azadirachta indica respectively

Table 1 Fungal endophytes isolated from Azadirachta indica the parts of the plants used, identity of the fungi, class, and references.

\begin{tabular}{lllllll}
\hline S/n & $\begin{array}{l}\text { Fungi } \\
\text { codes }\end{array}$ & $\begin{array}{l}\text { Plant } \\
\text { source }\end{array}$ & $\begin{array}{l}\text { Plant } \\
\text { parts }\end{array}$ & Identified as & Class & References \\
\hline $\mathbf{1}$ & AIL1 & A. indica & Leaf & Aureobasidium $s p$. & Hyphomycetes & {$[22,23]$} \\
$\mathbf{2}$ & AIL3 & A. indica & Leaf & Sordaria $s p$. & Ascomycetes & {$[22]$} \\
$\mathbf{3}$ & AIS1 & A. indica & Stem & Aspergillus $s p$. & Basidiomycetes & {$[22,24]$} \\
$\mathbf{4}$ & AIS2 & A. indica & Stem & Penicillium $s p$. & Hyphomycetes & $\begin{array}{l}\text { http://blast.ncbi.nlm.nih.g } \\
\text { ov/Blastin Genbank }\end{array}$ \\
\hline
\end{tabular}

Table 2 Molecularly identified endophytic fungus (Sordaria sp.)

\begin{tabular}{|c|c|c|c|c|c|}
\hline $\begin{array}{l}\text { Isolate } \\
\text { code }\end{array}$ & $\begin{array}{l}\text { Genbank } \\
\text { number }\end{array}$ & $\begin{array}{l}\text { Strain } \\
\text { reference }\end{array}$ & $\%$ Identity & $\begin{array}{l}\text { Query } \\
\text { length }\end{array}$ & Isolate name \\
\hline AIL3 & KF435432.1 & P44E2 [25] & 100 & 513 & Sordaria sp. \\
\hline
\end{tabular}




CAACACGGATCTCTTGGTTCTGGCATCGATGAAGAACGCAGCGAAATGCGATAAGTAATGTGAATTGCAGAATTCAGTGAA
TCATCGAATCTTTGAACGCACATTGCGCTCGCCAGTATTCTGGCGAGCATGCCTGTTCGAGCGTCATTTCAACCATCAAGCT
CTGCTTGCGTTGGGGATCCGCGGCTGCCCGCGGTCCCTCAAAAACAGTGGCGGGCTCGCTAGTCACACCGAGCGTAGTAACT
CTACATCGCTATGGTCGTGCGGCGGGTTCTTsGCCGTAAAACCCCCAATTTCTAAGGTTGACCTCGGATCAGGTAGGAATAC
CCGCTGAACTTAAGCATATCAATAA

The result of the antimicrobial activity of the fungal extracts is shown in Table 3.The fungal extracts at $1 \mathrm{mg} / \mathrm{mL}$ demonstrated varying degrees of antimicrobial activity against the test bacteria and fungi. Extract of AIL1(Aureobasidium sp.) showed antibacterial activity with IZD in the range of 4 to $8 \mathrm{~mm}$ against P. aeruginosa, 2 to 7 $\mathrm{mm}$ against $S$. typhi and 2 to $6 \mathrm{~mm}$ against $B$. subtilis. It showed antifungal activity against $C$. albicans, IZD in the range of 2 to $4 \mathrm{~mm}$. Extracts of AIL3 (Sordaria sp.) demonstrated antibacterial activity against all the bacterial strains tested with IZD ranging from 3 to $8 \mathrm{~mm}$ for $S$. aureus, 4 to $11 \mathrm{~mm}$ for P. aeruginosa, 2 to $6 \mathrm{~mm}$ for $S$. typhi, 3 to $10 \mathrm{~mm}$ for $K$. pneumoniae and 2 to $5 \mathrm{~mm}$ for $B$. subtilis but exhibited no antifungal activity against the tested fungi. Extract of AIS1 (Aspergillus sp.) showed antibacterial activity against Gram-negative P. aeruginosa (IZD, 2 to $7 \mathrm{~mm}$ ), S. typhi (IZD, 3 to 6 $\mathrm{mm}$ ) and Gram-positive B. subtilis (IZD, 2 to $6 \mathrm{~mm}$ ). The fungal extract additionally showed antifungal activity against C. albicans (IZD, 2 to $5 \mathrm{~mm}$ ). Extract of AIS2 (Penicillium sp.) demonstrated antibacterial activity against all the Gramnegative bacteria tested giving an inhibition zone diameter in the range of 2 to $8 \mathrm{~mm}$ for P. aeruginosa, 2 to $6 \mathrm{~mm}$ for $S$. typhi and 2 to $6 \mathrm{~mm}$ for K. pneumoniae. Antifungal activity was shown against C. albicans (IZD, 2 to $3 \mathrm{~mm}$ ).

Table 3 Antimicrobial activity of the endophytic fungi (zones of inhibition in $\mathrm{mm}$ )

\begin{tabular}{lllllll}
\hline & \multicolumn{2}{l}{$\begin{array}{l}\text { Endophytic fungal extract } \\
\text { (1 } \mathbf{~ m g} / \mathbf{m L})\end{array}$} & $\begin{array}{l}\text { Positive } \\
\text { Control }\end{array}$ & $\begin{array}{l}\text { Negative } \\
\text { control }\end{array}$ \\
\hline Test organisms & AILI & AIL3 & AIS1 & AIS2 & $\begin{array}{l}\text { Ciprofloxacin } \\
(5 \mu \mathrm{\mu g} / \mathrm{mL})\end{array}$ & $\begin{array}{l}\text { DMSO } \\
(100 \% \mathrm{v} / \mathrm{v})\end{array}$ \\
S. aureus & 0 & 8 & 0 & 0 & 6 & 0 \\
P. aeruginosa & 8 & 11 & 7 & 8 & 4 & 0 \\
S. typhi & 0 & 6 & 6 & 6 & 10 & 0 \\
K. pneumonia & 7 & 10 & 0 & 6 & 24 & 0 \\
B. subtilis & 6 & 5 & 6 & 0 & 8 & 0 \\
& & & & & Miconazole $(50 \mu \mathrm{g} / \mathrm{mL})$ & DMSO $(100 \% \mathrm{v} / \mathrm{v})$ \\
C. albicans & 4 & 0 & 5 & 3 & 15 & 0 \\
A. niger & 0 & 0 & 0 & 0 & 8 & 0 \\
\hline
\end{tabular}

The result of the Minimum Inhibitory Concentrations (MICs) of the different fungal endophyte crude extracts is shown in Table 4. Extract of AIL1 had MIC of $0.125 \mathrm{mg} / \mathrm{mL}$ for $K$. pneumoniae, $0.25 \mathrm{mg} / \mathrm{mL}$ for C. albicans and $0.25 \mathrm{mg} / \mathrm{mL}$ for P. aeruginosa. Extract of AIL3 had an MIC of $0.25 \mathrm{mg} / \mathrm{mL}$ for S. aureus and B. subtilis; $0.125 \mathrm{mg} / \mathrm{mL}$ for S. typhi and $0.0625 \mathrm{mg} / \mathrm{mL}$ for P. aeruginosa and K. pneumoniae. Extract of AIS1 showed MIC of $0.25 \mathrm{mg} / \mathrm{mL}$ for B. subtilis, S. typhi and C. albicans and $0.125 \mathrm{mg} / \mathrm{mL}$ against $P$. aeruginosa. Extract of AIS2 had MIC of $0.125 \mathrm{mg} / \mathrm{mL}$ for B. subtilis, $P$. aeruginosa, S. typhi and K. pneumonia and MIC of $0.5 \mathrm{mg} / \mathrm{mL}$ for $C$. albicans. The chromatograms of the isolated fungal endophytes extracts as revealed by High Pressure Liquid Chromatography-Diode Array Detector (HPLC-DAD) analysis are shown in Figures 2 numbered 1, 2, 3 and 4 for AIL1, AIL3, AIS1 and AIS2 respectively.

Table 4 Minimum inhibitory concentrations (MICs) of the fungal extracts

\begin{tabular}{llllllll}
\hline Fungal & \multicolumn{7}{c}{ Minimum inhibitory concentration (MIC) $\mathbf{m g} / \mathbf{m L}$} \\
\cline { 2 - 9 } & S. & B. & S. & $P$. & K. & $A$. & C. \\
& aureus & subtilis & tyhpi & aeruginosa & pnuemoniae & niger & albicans \\
AILI & - & 0.125 & - & 0.125 & 0.125 & - & 0.25 \\
AIL3 & 0.25 & 0.25 & 0.125 & 0.0625 & 0.0625 & - & - \\
\hline
\end{tabular}


Ujam et al. / GSC Biological and Pharmaceutical Sciences, 2020, 11(03), 115-124

\begin{tabular}{llllllll}
\hline AIS1 & - & 0.25 & 0.25 & 0.125 & - & - & 0.25 \\
AIS2 & - & - & 0.125 & 0.125 & 0.125 & - & 0.50 \\
\hline
\end{tabular}

S. aureus $=$ Staphylococcus aureus, B. subtilis $=$ Bacillus subtilis, S. typhi $=$ Salmonella typhi, P. aeruginosa $=$ Pseudomonas aeruginosa, K. pnuemoniae $=$ Klebsiella pnuemoniae, A. niger $=$ Aspergillus niger, C. albicans = Candida albicans

The bioactive compounds identified/detected at different peak levels are represented alphabetically. The UV spectra of the detected compounds are shown in Figure 3: these include (A) Glucobrassicin from AIL1; (B) Ferulic acid from AIL3; (C) 4-methoxybenzaldehyde, (D) 12-Hydroxy-16-scalaren, (E) 12-0-deacetyl-12-epi-scalarin, (F) Ixoside from AIS1; and (G) Citreodrimene F, (H) Cytosporin D from AIS2. Some of the detected compounds were unknown (Figures 3).

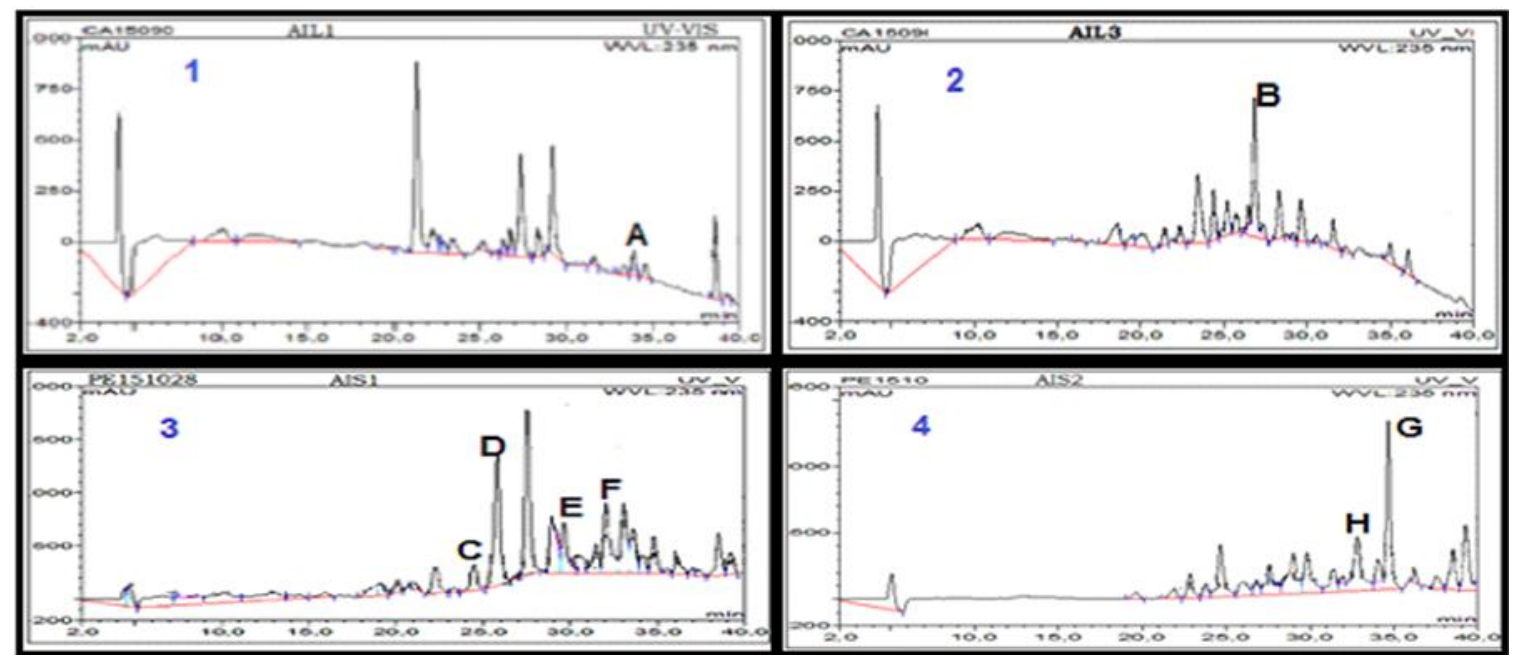


Figure 2 HPLC-DAD chromatograms (1, 2, 3 and 4) of the extracts of the endophytic fungi (AIL1, AIL3, AIS1 and AIS2) respectively isolated from Azadirachta indica showing the detected bioactive compounds.

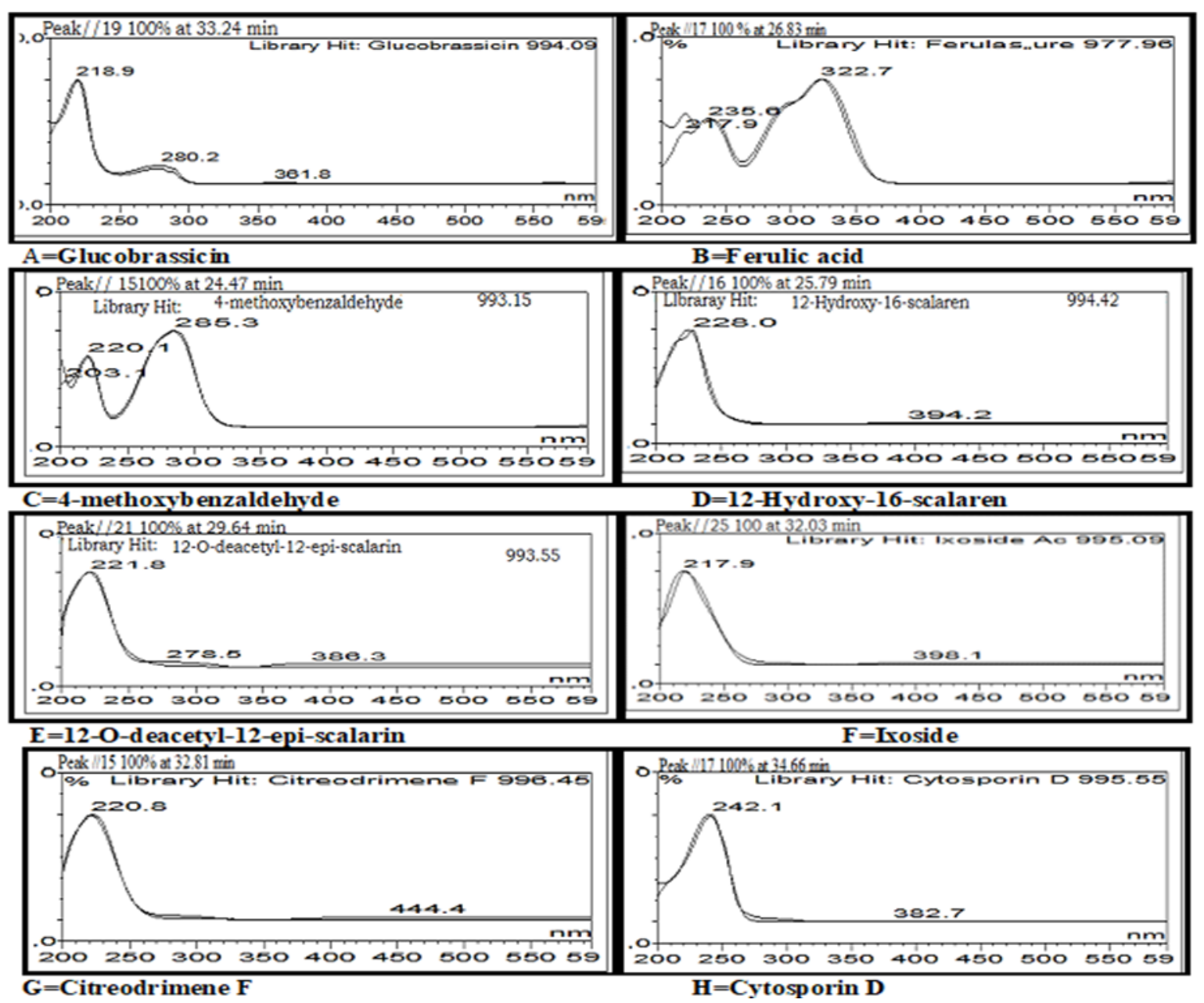

Figure 3 UV-spectra of the bioactive compounds detected (A-H)

\section{Discussion}

Endophytic microorganisms are ubiquitous, having been encountered in many plant species growing under natural conditions $[26,27]$. Endophytic fungi, in particular, have been investigated in a variety of plants ranging from grasses $[28,29]$ to trees $[12,15,30,31]$.

In this study, a total of four (4) endophyte fungal isolates were obtained from the leaves and stem segments of Azadirachta indica. Morphological (macroscopic and microscopic) characteristics (Fig. 1) resulted in the identification of three of the endophytic fungi isolates AIL1, AIS1 and AIS2 as Aureobasidium sp., Aspergillus sp., and Penicillium sp. respectively (Table 1). One of the endophytic fungal isolates (AIL3) was further identified by internal transcribed spacer. The BLAST search sequence similarity found against the existing non-redundant nucleotide sequence database identified the percentage of similarity between the fungus and database. The fungi AIL3 was confirmed as Sordaria sp., strain-P44E2 and given accession number-KF435432.1; in NCBI GenBank database (http://blast.ncbi.nlm.nih.gov/Blast.cgi) (Table 2).

The isolated fungal endophytes belong to classes Hyphomycetes, Ascomycetes and Basidiomycetes. Out of the total fungal endophytes isolated, half (50\%) of the genera are from hypomycetes. Verma et al. (2011) [32] isolated Alternaria sp., Acromonium sp., Cladosporium sp. and Aspergillus sp. from Azadirachta indica. The group also reported the presence of Pestalotiopsis, Trichoderma, Curvularia and Penicillium sp. Taware and Rajurkar [8] also reported the isolation of Alternaria sp. and Trichoderma sp. from some Nigerian medicinal plants. Our study is the first report on the isolation of Sordaria sp. and Aureobasidium sp. from Azadirachta indica. It is possible that our findings differed from the previous reports due to factors such as geographical and seasonal differences 
In recent years, considerable attention has been given to fungi and this has resulted in a large number of studies involving a variety of approaches [27,32]. Focus has also been on the exploration of secondary metabolites of fungi to obtain new bioactive molecules with potential applications in the medical, pharmaceutical, industrial, agricultural and environmental fields $[12,13,31$,

HPLC analysis revealed the presence of some bioactive compounds in the extracts of the isolated fungi. Citreodrimene $\mathrm{F}$ and Cytosporin D were previously reported to have antimicrobial, antiplasmodial and immunomodulatory properties $[33,34,35]$. Some of the extracts of the endophytic fungal isolates contain many undetected/unknown bioactive compounds which could also be contributing to the biological activities they displayed. The undetected compounds or compounds whose spectra had no library hit/match may represent important or novel bioactive compounds with interesting pharmaceutical or industrial applications [14].

Ethyl acetate extract of Areobasiduim sp. (AIL1) exhibited antibacterial activity against K. pneumoniae, P. aeruginosa and $B$. subtilis but lacked activity against $S$. aureus and $S$. typhi. In addition, the extract showed antifungal activity against $C$. albicans but was in-active against $A$. niger. The identity of the major bioactive compounds in the extract could not be revealed by HPLC-DAD analysis.

Extract of Sordaria (AIL3) was most active of all, showing a broad-spectrum antibacterial activity against the test Grampositive and Gram-negative bacteria (S. aureus, P. aeruginosa, S. typhi, K. pneumoniae and B. subtilis) though it showed no antifungal activity against the test fungi; $C$. albicans and Aspergillus niger. The HPLC-DAD analysis of the extract revealed that it contains the bioactive compound ferulic acid which was previously reported to inhibit the growth of both Gram-positive and negative bacteria [34]. The result of this study is consistent with their findings. Extract of Aspergillus sp. (AIS1) showed antimicrobial activity against $S$. subtilis, $P$. aeruginosa, $S$. typhi and C. albicans but no activity against $S$. aureus, $K$. pneumoniae and A. niger. Extract of Penicillium sp. (AIS2) showed antimicrobial activity against all the test Gram negative bacteria but showed no activity against the Gram-positive ones.

The antimicrobial activity of the fungal endophytes extracts against the test microorganisms (bacteria and fungi) was moderate. Thus, it could be inferred that extracts of the endophytic fungi from $A$. indica make up a reliable source of bioactive compounds, as shown by the wide range of compounds with diverse biological properties present in these extracts.

\section{Conclusion}

Our results showed the diversity of endophytic fungi in the leaves and stems of $A$. indica and significant of these fungi as promising source for bioactive compounds with antimicrobial potential. Additional studies are required to identify the unknown compounds detected in the extracts.

\section{Compliance with ethical standards}

\section{Acknowledgments}

The authors wish to thank the laboratory workers in different labs where this study was carried out. We are also grateful to the taxonomist, Mrs Anthonia U. Emezie who authenticated the plant materials used in the study.

\section{Disclosure of conflict of interest}

Authors Ujam Nonye T., Abba Chika C. , Eze Peter M., Oli Angus N., Ejikeugwu Chika, Ugwu Malachy C., Okoye Festus B.C. and Esimone Charles O. declare that they have no conflict of interest.

\section{References}

[1] Menpara D and Chanda S. (2013). Endophytic bacteria-unexplored reservoir of antimicrobials for combating microbial pathogens. Microbial pathogens and strategies for combating them: Science, technology and education, 1095-103.

[2] Hardoim PR, van Overbeek LS, Berg G, Pirttilä AM, Compant S, Campisano A and Döring, M. (2015). The Hidden World within Plants: Ecological and Evolutionary Considerations for Defining Functioning of Microbial Endophytes. Microbiol. Mol. Biol. Rev, 79, 293-320. 
[3] Verma VC, Gond SK, Kumar A, Mishra A, Kharwar RN and Gange AC. (2008). Endophytic Actinomycetes from Azadirachta indica A. Juss.: Isolation, Diversity, and Anti-microbial Activity. Microb. Ecol, 57, 749-756.

[4] Subbulakshmi GK, Thalavaipandian A, Bagyalakshmi VR and Rajendra A. (2012). Bioactive endophytic fungal isolates of Biota orientalis (L) Endl., Pinus excelsa Wall and Thuja occidentalis L. International Journal of Advanced Life Sciences,4, 1-7.

[5] Strobel G, Daisy B, Castillo U and Harper J. (2004). Natural Products from Endophytic Microorganisms. Journal of Natural Product, 67, 257-268.

[6] Verma VC, Singh SK and Kharwar RN. (2012). Histological Investigation of Fungal Endophytes in Healthy Tissues of Azadirachta indica A. Juss. Kasetsart J. Nat. Sci, 46, 229-237.

[7] Rajagopal K, Maheswari S and Kathiravan G. (2012). Diversity of endophytic fungi in some tropical medicinal plants-A report. Afr. J. Microbiol. Res, 6, 2822-2827.

[8] Taware AS and Rajurkar SK. (2015). Diversity assessment of endophytic fungi from Azadirachta indica A. Juss from various regions of Aurangabad, Maharashtra (India).International Journal of Innovative Science, Engineering \& Technology, 2(7), 2348 - 7968.

[9] Strobel G and Daisy B. (2003). Bioprospecting for microbial endophytes and their natural products. Microbiol. Mol. Biol. Rev, 67(4), 491-502.

[10] Okoye FB, Lu S, Nworu CS, Esimone CO, Proksch P, Chadli A and Debbab A.(2013). Depsidone and diaryl ether derivatives from the fungus Corynespora cassiicola, an endophyte of Gongronema latifolium. Tetrahedron Letters, 7, 54(32), 4210-4.

[11] Okoye FB, Nworu CS, Akah PA, Esimone CO, Debbab A and Proksch P. (2013). Inhibition of inflammatory mediators and reactive oxygen and nitrogen species by some depsidones and diaryl ether derivatives isolated from Corynespora cassiicola, an endophytic fungus of Gongronema latifolium leaves. Immunopharmacol Immunotoxicol, 35(6), 662-8.

[12] Okoye FBC, Nworu CS, Debbab A, Esimone CO and Proksch P. (2015). Two new Cytochalasins from an endophytic fungus, KL-1.1 isolated from Psidium guajava leaves. Phytochem. Lett, 14, 51-55.

[13] Chen H, Daletos G, Okoye F, Lai D, Dai H and Proksch P.(2015). A new cytotoxic cytochalasin from the endophytic fungus Trichoderma harzianum. Natural product communications, 10(4), 1934578X1501000412.

[14] Akpotu MO, Eze PM, Abba CC, Umeokoli BO, Nwachukwu CU, Okoye FB and Esimone C0. (2017). Antimicrobial activities of secondary metabolites of endophytic fungi isolated from Catharanthus roseus. Journal of Health Sciences, 7(1), 15-22.

[15] Ujam NT, Eze PM, Chukwunwejim CR, Okoye FB and Esimone CO. (2019). Antimicrobial and immunomodulatory activities of secondary metabolites of an endophytic fungus isolated from Ageratum conyzoides. Current Life Sciences, 5 (1), 19-27.

[16] Melissa Petruzzello. (2019). Neem. Encyclopædia Britannica. Encyclopædia Britannica, inc. URL.

[17] Panda SK, Padhi L, Leyssen P, Liu M, Neyts J and Luyten W. (2017). Antimicrobial, Anthelmintic, and Antiviral Activity of Plants Traditionally Used for Treating Infectious Disease in the Similipal Biosphere Reserve, Odisha, India. Front Pharmacol, 23(8), 658.

[18] Orwa C, Mutua A, Kindt R, Jamnadass R and Anthony S. (2009). Agroforestree Database:a tree reference and selection guide version, 4.0 .

[19] Li GH, Yu ZF, Li X, Wang XB, Zheng LJ and Zhang KQ. (2007). Nematicidal metabolites produced by the endophytic fungus Geotrichum sp. AL4. Chem Biodivers, 4, 1520-152.

[20] Arnold AE, Maynard Z, Gilbert GS, Coley PD and Kursar TA. (2000). Are tropical fungal endophytes hyperdiverse? Ecol. Lett, 3, 267-274.

[21] Pragathi D, Vijaya T, Mouli KC and Anitha D. (2013). Diversity of fungal endophytes and their bioactive metabolites from endemic plants of Tirumala hills-Seshachalam biosphere reserve, 12(27), 4317-4323.

[22] Ellis DH, Davis S, Alexiou H, Handke R and Bartley R. (2007). Descriptions of medical fungi (61-167). Adelaide: University of Adelaide. 
[23] Rainer J and De Hoog GS. (2006). Molecular taxonomy and ecology of Pseudallescheria, Petriella and Scedosporium prolificans (Microascaceae) containing opportunistic agents on humans. Mycological research, $110(2), 151-60$.

[24] Frisvad JC and Samson RA. (2004). Polyphasic taxonomy of Penicillium subgenus Penicillium. A guide to identification of food and air-borne terverticillate Penicillia and their mycotoxins. Studies in mycology, 49(1), 174.

[25] Beckler MD, Higginbotham JN, Franklin JL, Ham AJ, Halvey PJ, Imasuen IE, Whitwell C, Li M, Liebler DC and Coffey RJ.(2013). Proteomic analysis of exosomes from mutant KRAS colon cancer cells identifies intercellular transfer of mutant KRAS. Molecular \& cellular proteomics, 12(2), 343-55.

[26] Rodriguez RJ, White Junior JF, Arnold AE and Redman RS. (2009). Fungal Endophytes: Diversity and Functional Roles. The New Phytologist, 182 (2), 314-330.

[27] Nisa H, Kamili AN, Nawchoo IA, Shafi S, Shameem N and Bandh SA. (2015). Fungal Endophytes as Prolific Source of Phytochemicals and Other Bioactive Natural Products: A Review. Microbial Pathogenesis, 82, 50-59.

[28] Müller CB and Krauss J. (2005). Symbiosis between Grasses and Asexual Fungal Endophytes. Current Opinion in Plant Biology, 8(4), 450-456.

[29] Rekha D and Shivana MB. (2014). Diversity, Antimicrobial and Antioxidant Activities of Fungal Endophytes in Cynodon Dactylon (L.) Pers. and Dactyloctenium Aegyptium (L.) P. Beauv. International Journal of Current Microbiology and Applied Science, 3(8), 573-591.

[30] Arnold AE, Mejia LC, Kyllo D, Rojas EI, Maynard Z, Robbins N and Herre EA. (2003). Fungal Endophytes Limit Pathogen Damage in a Tropical Tree. Proceedings of the National Academy of Sciences (Pnas), 100(26), 1564915654.

[31] Campos FF, Sales Júnior PA, Romanha AJ, Araújo MSS, Siqueira EP, Resende JMR, Alves TMA, Martins-Filho AO, Santos VL, Rosa CA, Zani CL and Costa BB. (2015). Bioactive Endophytic Fungi Isolated From Caesalpinia echinata Lam. (Brazilwood) And Identification Of Beauvericin As Atrypanocidal Metabolite From Fusarium sp. Memórias Do Instituto Oswaldo Cruz, 110, 65-74.

[32] Verma Vijay C, Gond Surendra K, Kumar Anuj, Kharwar Ravindra N, Boulanger Lori-Ann and Strobel Gary A. (2011). Endophytic Fungal Flora from Roots and Fruits of an Indian Neem Plant Azadirachta indica A. Juss., and Impact of Culture Media on their Isolation. Indian J Microbiol, 51(4), 469-476.

[33] Abonyi Dominic O, Eze Peter M, Abba Chika C, Ujam Nonye T, Proksch Peter, Okoye Festus BC and Esimone Charles 0. (2018).Biologically active phenolic acids produced by Aspergillus sp., an endophyte of Moringa oleifera. European Journal of Biological Research, 8 (3), 158-168.

[34] Brenelli de Paiva L, Goldbeck R, Dantas dos Santos W and Squina FM. (2013). Ferulic acid and derivatives: molecules with potential application in the pharmaceutical field. Brazilian Journal of Pharmaceutical Sciences, 49(3), 395-411.

[35] Dalvi SN and Garge SS. (2011). Synthesis and Biological activity for 4-Methoxyphenyl (pyrazin-2-yl) Methanone and its detection by GC-MS Techniques. Research Journal of Chemical Sciences, 1(5), 85-87.

\section{How to cite this article}

Ujam NT, Abba CC, Eze PM, Oli AN, Ejikeugwu CE, Ugwu MC, Okoye FBC and Esimone C0. (2020). The isolation, identification and antimicrobial activities of endophytic fungi from Azadirachta indica. GSC Biological and Pharmaceutical Sciences, 11(3), 115-124. 